\title{
Cross-reactivity of Antiserum to Absidia cylindrospora among Some Mucorales and Other Fungi
}

\author{
By OSAMU HAYASHI, TOSHIRO YADOMAE, HARUKI YAMADA \\ AND TOSHIO MIYAZAKI \\ Department of Microbial Chemistry, Tokyo College of Pharmacy, \\ 1432-1 Horinouchi, Hachioji, Tokyo 192-03, Japan
}

(Received 3 May 1978)

\section{INTRODUCTION}

Mannose-containing heteroglycans such as galactomannans and rhamnomannans are known fungal antigenic substances. Relationships between serological reactivity, chemical structure and species specificity of these glycans have been examined in some species. In the case of Mucorales, however, the serological cross-reactivity has not been examined in detail. Previously, we isolated the serologically active substance of Absidia cylindrospora, a member of the Mucorales, from the supernatant of disrupted mycelium and characterized it as a fucomannan-peptide (Hayashi et al., 1978). The fucomannan-peptide reacted with rabbit antiserum (anti-ACE serum) against the non-dialysable fraction of the culture filtrate of $A$. cylindrospora. The present communication is concerned with the cross-reactivities of antigenic fractions from four Mucor species, Rhizopus nigricans and 10 species of fungi belonging to the Oomycetes or Fungi Imperfecti.

\section{METHODS}

Organisms. Absidia cylindrospora IFO 4000, Rhizopus nigricans IAM 6070, Mucor hiemalis IFO 5303, $M$. javanicus IFo 4569, M. lamprosporus IFo 6337, M. mucedo IFo 5776, Pythium debaryanum IFo 5919, Alternaria solani IFo 5924, Aspergillus niger IFo 4043, A. parasiticus IFO 4301, Cladosporium herbarum IFo 4459, Fusarium solani IFo 5232 and Penicillium islandicum IFo 5234 were cultured in Sabouraud's liquid medium with shaking for 2 weeks at $27^{\circ} \mathrm{C}$.

Preparation of antigens from the various organisms. Cultured mycelium suspended in cold saline was homogenized in a Waring blender (Nihon Seiki Seisakusho Co., Japan) and then treated in a French press in the cold (Hayashi et al., 1978). The homogenized mycelium fluid was centrifuged at $3000 \mathrm{rev}$. $\mathrm{min}^{-1}$ for $10 \mathrm{~min}$, and the supernatnant was dialysed against distilled water for $3 \mathrm{~d}$ and then lyophilized. The resulting powder was designated the I-fraction.

Each culture filtrate was concentrated to a small volume after dialysis against distilled water for $3 \mathrm{~d}$, and 4 vol. ethanol was added to the concentrate. The precipitate was dried with acetone and ether, and designated the E-fraction.

Mannans and galactomannan were prepared according to methods described previously: mannans from Candida albicans (Duke strain) (Miyazaki, 1962) and from Saccharomyces cerevisiae (Peat et al., 1961) and galactomannan from Penicillium chrysogenum (Miyazaki \& Yadomae, 1968).

Preparation of $A C I-B, M h I-B$ and $R n I-B$. Serologically active fractions, ACI-B, MhI-B and RnI-B, were prepared from the I-fractions of $A$. cylindrospora, $M$. hiemalis and $R$. nigricans, respectively, as described previously (Hayashi et al., 1978) using affinity chromatography with concanavalin A-Sepharose, for which the B fractions had affinity.

Immunological procedures. Anti-ACE serum was prepared by immunizing a rabbit with the non-dialysable fraction of the culture filtrate of $A$. cylindrospora (Hayashi et al., 1978). Precipitin tests on E- and I-fractions obtained from various fungi were performed in fine glass tubes $(2 \times 50 \mathrm{~mm})$ using anti-ACE serum. Each of the E- and I-fractions was dissolved in saline to concentrations of $5 \mathrm{mg} \mathrm{ml}^{-1}$ and $500 \mu \mathrm{g} \mathrm{ml}^{-1}$, and was statically layered on the surface of undiluted anti-ACE serum in the fine glass tube. After incubation for 1 or $2 \mathrm{~h}$ at room temperature, each tube was inspected for the presence of a precipitin band. 


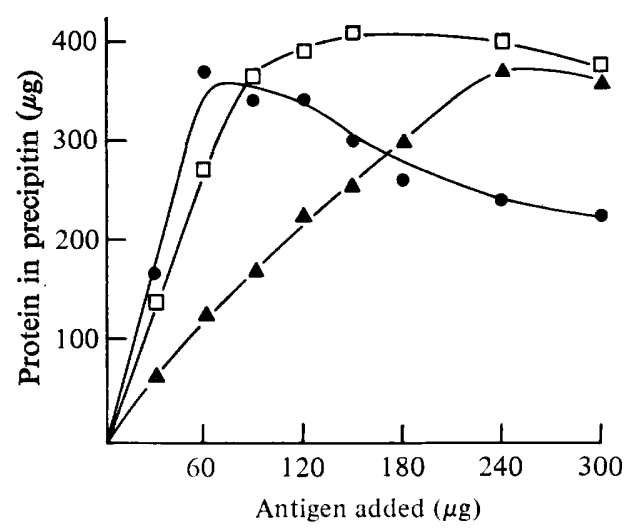

Fig. 1. Quantitative precipitin curves of ACI-B ( $)$, MhI-B (A) and RnI-B ( $\square$ ) against anti-ACE serum.

Quantitative precipitin tests of MhI-B, RnI-B and ACI-B against anti-ACE serum were carried out as follows: $0.2 \mathrm{ml}$ of undiluted rabbit antiserum was mixed with $0.1 \mathrm{ml}$ of serial dilutions of antigens in saline. The mixtures were incubated at $37^{\circ} \mathrm{C}$ for $1 \mathrm{~h}$, stored at $4^{\circ} \mathrm{C}$ for $90 \mathrm{~h}$ with occasional shaking and then centrifuged. The protein contents of the precipitated complexes were determined by the method of Lowry et al. (1951), using bovine serum albumin as a standard.

Immunodiffusion analysis and immunoelectrophoresis were carried out as described previously (Hayashi et al., 1978).

\section{RESULTS AND DISCUSSION}

Anti-ACE serum reacted with E- and I-fractions from $M$. hiemalis, $M$. javanicus, $M$. lamprosporus, $M$. mucedo and $R$. nigricans as well as those from $A$. cylindrospora. Samples prepared from Alternaria solani, Fusarium solani, Aspergillus spp., Cladosporium herbarum and Penicillium islandicum did not react with anti-ACE serum, although these species have mannose-containing glycans (Miyazaki \& Naoi, 1975; Gander, 1974). Pythium debaryanum, which belongs to Oomycetes in Phycomycetes, did not show any cross-reactivity. Previously, Hotchi (1967) observed cross-reactions between Absidia lichtheimi, Mucor globosus and Rhizopus nigricans by a fluorescent antibody technique. Antiserum against whole cells of $A$. lichtheimi gave a weak cross-reaction with a phenol extract of Candida albicans, but the serological cross-reactivities have not been elucidated in detail. In our experiments, neither purified mannans from S. cerevisiae (Peat et al., 1961) and C. albicans (Miyazaki, 1962) nor galactomannan from Penicillium chrysogenum (Miyazaki \& Yadomae, 1968) reacted with the antiserum to $A$. cylindrospora. These findings suggest that the anti-ACE serum has specificity only for Mucoraceae or Mucorales.

In immunodiffusion analysis of E-fractions from Mucor spp. and $R$. nigricans against anti-ACE serum, each of these active fractions gave a precipitin band which was identical with that of $A$. cylindrospora. The results of immunodiffusion analysis and immunoelectrophoresis of MhI-B and RnI-B, which were isolated from $M$. hiemalis and $R$. nigricans, also suggest that these fractions contained a common serologically active substance. Quantitative precipitin curves of MhI-B, RnI-B and ACI-B against anti-ACE serum are shown in Fig. 1.

From a serological examination of rhamnomannans prepared from Sporothrix schenckii and Ceratocystis species, Lloyd \& Travassos (1975) concluded that the rhamnosyl side chains were important as the immunochemical determinants; but from studies of galactomannans I prepared from five species of dermatophytes, Grappel et al. (1968) concluded that the mannopyranoside units were the predominant groups. In Mucorales, the role of fucose units in the immunological specificities of the fucomannan-peptide is not clear. Since the purified mannans of $C$. albicans and $S$. cerevisiae did not cross-react with the anti-ACE 
serum, it would appear that the chemical structure of the common immunological determinant of the serologically active substances of Mucorales may be different from those of the mannans. The chemical analysis of the common determinant is now under study.

We thank Misses S. Shiratsuchi and N. Kurihara for their technical assistance.

\section{REFERENCES}

GANDER, J. E. (1974). Fungal cell wall glycoproteins and peptide-polysaccharides. Annual Review of Microbiology 28, 103-119.

Grappel, S. F., Blank, F. \& Bishop, C. T. (1968). Immunological studies on dermatophytes. II. Serological reactivities of mannans prepared from galactomannans $I$ and II of Microsporium quickeanum, Trichophyton granulosum, Trichophyton interdigitale, Trichophyton rubrum and Trichophyton schoenleinii. Journal of Bacteriology 95, 1238-1242.

Hayashi, O., Yamada, H., Yadomae, T. \& MiYaZAKI, T. (1978). Purification and partial characterization of the serologically active substance from Absidia cylindrospora. Journal of General Microbiology 106, 289-295.

НотснI, M. (1967). The application of fluorescent antibody techniques to the identification of pathogenic fungi in tissue specimens. Medical Journal of Shinshu University 12, 123-139.

Lloyd, K. O. \& Travassos, L. R. (1975). Immunochemical studies on L-rhamno-D-mannans of Sporothrix schenckii and related fungi by use of rabbit and human antisera. Carbohydrate Research 40, 89-97.

Lowry, O. H., Rosebrough, N. J., FARr, A. L. \& Randall, R. J. (1951). Protein measurement with the Folin phenol reagent. Journal of Biological Chemistry 193, 265-275.

MiyazaKi, T. (1962). Studies on fungal polysaccharides. IV. On the chemical structure of mannan from Candida albicans. Yakugakuzassi 82, 1678-1680.

MiYazaKI, T. \& NaOI, Y. (1975). Chemical structures of main extracellular polysaccharides of Alternaria solani and Fusarium solani. Studies on fungal polysaccharides. XVIII. Chemical and Pharmaceutical Bulletin, Tokyo 23, 1752-1758.

MiYAZAKI, T. \& YADOMAE, T. (1968). Isolation of a water-soluble polysaccharide from the mycelium of Penicillium chrysogenum. Studies on fungal polysaccharides. V. Chemical and Pharmaceutical Bulletin, Tokyo 16, 1722-1725.

Peat, S., Whelan, W. J. \& Edwards, T. E. (1961). Polysaccharides of Baker's yeast. IV. Mannan. Journal of Chemical Society, 29-34. 